\title{
Isotopic composition of the precipitations in the central Mediterranean: Origin marks and orographic precipitation effects
}

\author{
Marcello Liotta, ${ }^{1}$ Rocco Favara, ${ }^{1}$ and Mariano Valenza ${ }^{2}$ \\ Received 25 October 2005; revised 6 June 2006; accepted 28 June 2006; published 4 October 2006.
}

[1] The isotopic composition of the rainfall in northwestern Sicily (Italy, central Mediterranean) was investigated in the period February 2002 to March 2003. A rain gauge network was installed and sampled monthly. The monthly values of the $\mathrm{D}$ and ${ }^{18} \mathrm{O}$ ratios showed a wide range that reflected seasonal climatic variations. Mean weighted values were used to define an isotopic model of precipitation. Temporal variations in deuterium excess were also investigated. Using mean volume weighted values, the Local Meteoric Water Line (LMWL) can be represented by the equation: $\delta \mathrm{D}=4.7 \delta^{18} \mathrm{O}-8.2$ $\left(\mathrm{r}^{2}=0.96\right)$. Deuterium excess $\left(\mathrm{d}=\delta \mathrm{D}-8 \delta^{18} \mathrm{O}\right)$ was found to be strongly related to orography. The coastline samples were characterized by mean weighted deuterium excess values close to $12.5 \%$; samples from inland areas showed values of $16 \%$, while samples taken from the main reliefs showed values close to $19 \%$. In inland areas, isotopic exchange between raindrops and moisture could shift the deuterium excess values slightly. On the higher reliefs, the interaction between falling raindrops and orographic clouds could shift the deuterium excess values significantly. The low slope of the LMWL could be referred to the high deuterium excess values of the higher sites and is related to orographic precipitation rather than to evaporation processes during the fall of the raindrops. The results obtained suggest that local orographic features may significantly change the isotopic composition of precipitation.

Citation: Liotta, M., R. Favara, and M. Valenza (2006), Isotopic composition of the precipitations in the central Mediterranean: Origin marks and orographic precipitation effects, J. Geophys. Res., 111, D19302, doi:10.1029/2005JD006818.

\section{Introduction and Background}

[2] Deuterium and oxygen isotopic ratios are often used as tracers to investigate hydrological paths. A good knowledge of the factors governing isotopic fractionation is helpful in understanding hydrogeological processes. The deuterium-excess parameter $d$, defined by Dansgaard [1964] as $d=\delta \mathrm{D}-8 \delta^{18} \mathrm{O}$, is one of the most useful isotopic tools in defining the formation site and trajectories of atmospheric moisture that give rise to precipitation. It has been observed to be essentially fixed at the site of sea-air interactions [Craig and Gordon, 1965]. Gat and Carmi [1970] used data with abundant rainfall in order to minimize the effects resulting from the evaporation of falling drops, and they stressed the role of the interaction between air masses and the Mediterranean Sea in governing the deuterium excess of precipitations. Later Rindsberger et al. [1983] showed that the isotopic compositions of precipitations in coastal east Mediterranean areas can serve as an information source regarding air mass origin and trajectories. Using long-term mean monthly values of the stations

\footnotetext{
${ }^{1}$ Istituto Nazionale di Geofisica e Vulcanologia-Sezione di Palermo, Palermo, Italy.

${ }^{2}$ Dipartimento di Chimica e Fisica della Terra, Università degli Studi di Palermo, Palermo, Italy.

Copyright 2006 by the American Geophysical Union. 0148-0227/06/2005JD006818
}

included in the Global Network for Isotopes in Precipitation (GNIP) database, Araguás- Araguás et al. [2000] observed that in the Northern Hemisphere deuterium excess varies seasonally showing lower values than $10 \%$ during summer months and higher values during winter months. Cruz-San Julian et al. [1992] described the correlation between $d$-excess values of precipitation and altitude in southeastern Spain as being the result of the evaporation of raindrops below the cloud base; so that the lower $d$-excess values of precipitation at sea level would be the result of a higher degree of evaporation of raindrops. Recently, the relationships between the isotopic composition of precipitation in the Mediterranean Basin and air circulation patterns and climate have been highlighted by International Atomic Energy Agency [2005]. The authors would therefore underline the promising role of the isotopic approach which could be used as an additional parameter when monitoring changes in circulation patterns. In many cases deuterium excess has been used to describe very different phenomena that are, everywhere, related to nonequilibrium fractionation processes.

[3] When we investigate the isotopic composition of precipitation we should distinguish between the Synoptic and Mesoscale and the convective scales. In fact, while the first two cover phenomena between $20 \mathrm{~km}, 2,000 \mathrm{~km}$ and more, and give us isotopic information regarding air mass trajectories and/or vapor origin, the last one, i.e., the convective scale, covers phenomena between 0.2 and 


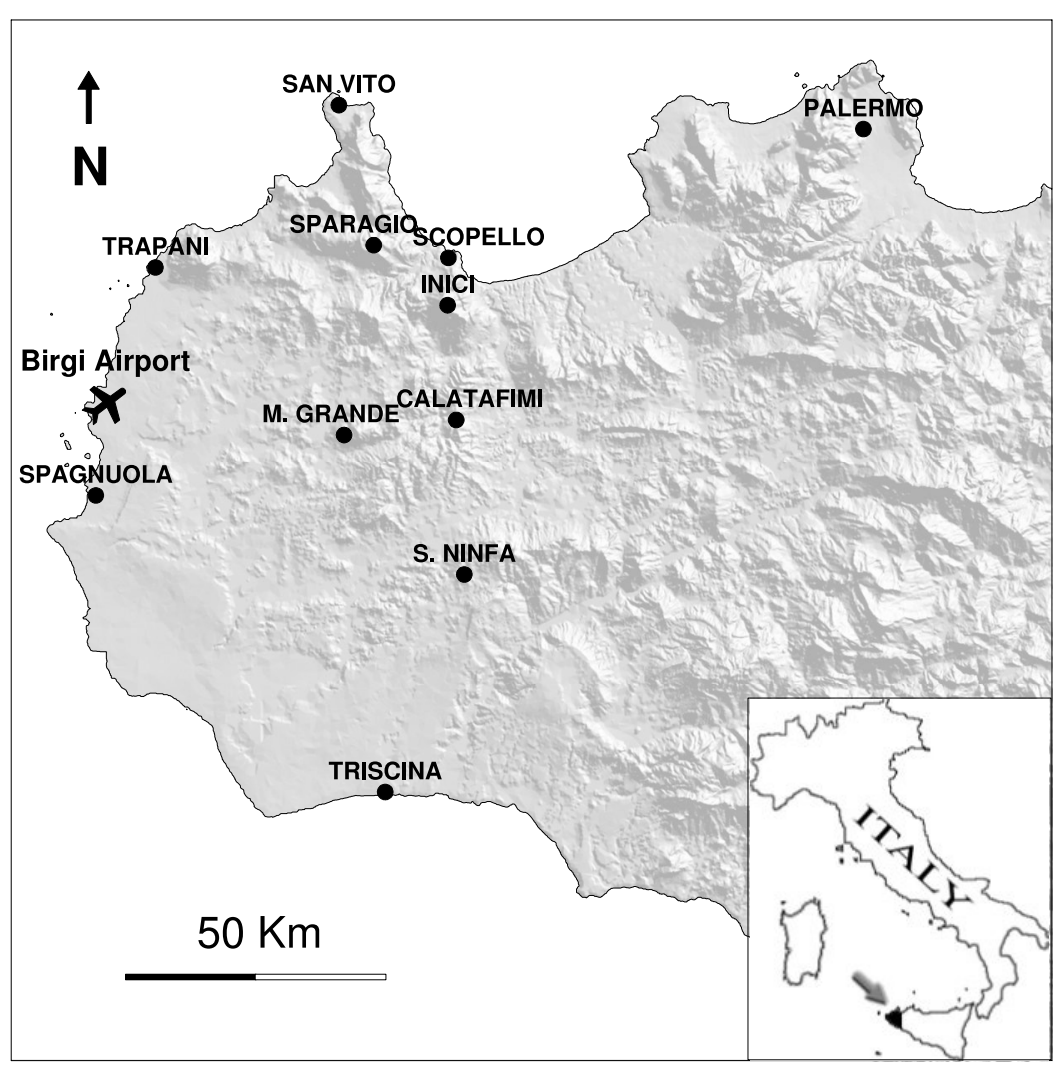

Figure 1. Scheme map of the studied area. Rain gauge grid is shown by solid circles.

$20 \mathrm{~km}$ [Houze, 1993] and gives us information about local effects.

[4] The main objective of this work is to define an isotopic composition model of precipitation in the central Mediterranean, capable of distinguishing between largescale processes and local ones. To reach this aim a highdensity network of rain gauges has been used.

\section{Methods}

[5] A rain gauge network was installed in northwestern Sicily (Figure 1). The sites were chosen with the aim of accurately investigating the relationship between the isotopic composition of rainwater and the local morphological features. All the stations were sampled monthly and about $350 \mathrm{cc}$ of Vaseline oil were added in order to avoid evaporation processes. The amount of precipitation was also registered and air temperature data were collected at the climatic station located at Trapani-Birgi Airport. To relate storm trajectories to isotopic marks of precipitation, infrared satellite images and synoptic charts were obtained and analyzed (images from EUMETSAT dissemination service, synoptic charts from (C) British Crown copyright 2006, published by the Met Office UK).

[6] $\mathrm{D} / \mathrm{H}$ water measurements were carried out using the Kendall and Coplen [1985] technique (reaction with zinc at $450^{\circ}$ ) and a mass spectrometer Finnigan Mat Delta Plus, while ${ }^{18} \mathrm{O} /{ }^{16} \mathrm{O}$ measurements were carried out by means of the $\mathrm{CO} 2$-water equilibration technique [Epstein and Mayeda, 1953] using a mass spectrometer Analytical Precision AP2003. The analyses were performed at the Istituto
Nazionale di Geofisica e Vulcanologia (INGV), Palermo Department. The isotope ratios are expressed as deviation per mil $(\delta$ in $\%$ o) from reference V-SMOW. The uncertainties are $\pm 0.1 \%$ and $\pm 1 \%$ of $\delta^{18} \mathrm{O}$ and $\delta \mathrm{D}$ respectively.

\section{Climatic Setting}

[7] The Sicilian climate is a typically Mediterranean one. The Mediterranean climate is a special type of climate characterized by hot summer droughts and winter rain in the midlatitudes, north of the subtropical climate zone. In summer, the subtropical high-pressure cells drift toward the Northern Hemisphere (from May to August). This coincides with substantially higher temperatures than in winter and little rainfall (Figure 2). During the winter, the high-pressure cells drift back toward the equator, and the weather is dominated by cyclonic storms [Bolle, 2003]. Perturbations, generated prevalently in winter-spring in the west, move along northwest trajectories when the fronts are cold, and along southwest trajectories when the perturbations are hot. At ground level the mean monthly relative humidity is always higher than $70 \%$ and close to $80 \%$ during the rainy season (Figure 2). Climatic features and calcareous soil are responsible for the poor vegetation coverage of the studied area.

\section{Results}

[8] The Mediterranean climate is characterized by a cold rainy season and a hot dry one. Therefore, when all the monthly values are used to define a local meteoric water 


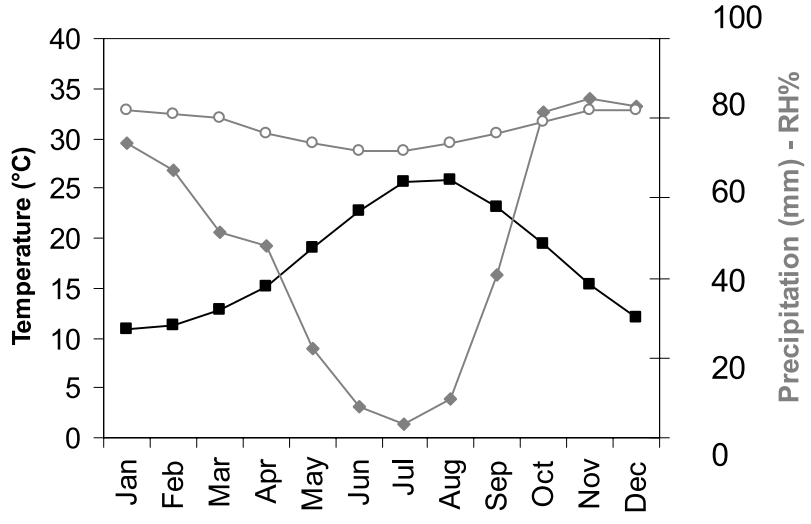

Figure 2. Mean values of air temperature (right axis), precipitation and relative humidity (left axis) at Trapani Birgi Airport.

line, said line will be strongly influenced by extreme values. (Figure 3). In fact, during the hot months only small amounts of rain fall and their isotopic abundances are very different from those of the other months. Sometimes these abundances reflect effects such as caused by the evaporation of raindrops during the fall itself (e.g., July 2002 samples from S. Vito and Triscina, see Table 1). On the other hand, some samples taken during the cold months show very negative values that may be ascribed to cold air masses coming from the north (e.g., December 2002 samples). We have therefore preferred to use volume weighted values that reflect the main processes involved.

[9] Weighted isotopic composition data of the monthly rain samples were computed for the period April 2002 to March 2003 (Table 2). The deuterium excess parameter $d$ was computed according to Dansgaard [1964] definition $d=$ $\delta \mathrm{D}-8 \delta^{18} \mathrm{O}$. Coastal sites show similar isotope ratios; close to -6.3 for oxygen and $-38 \delta \%$ for hydrogen. These values are more negative with respect to the weighted mean value found by Celle-Jeanton et al. [2001] for the western Mediterranean region during the period 1985-1991 $\left(-4.45 \delta^{18} \mathrm{O}\right.$ and $-25.96 \delta \%$ at Tunis $)$. Such differences could be explained by taking the long-term relation between isotopic composition of precipitation and climate into account. As shown by Rozanski et al. [1992], the weighted mean value significantly increased (more than $1 \delta \%$ ) between 1986 and 1990 in response to the temperature increase, as compared with the 1970 to 1990 average.

[10] The altitude effect was estimated by plotting weighted isotopic composition versus the altitude of the rain gauges (Figure 4a). The linear regression equation is:

$$
\delta^{18} \mathrm{O} / \%=-(0.0018 \pm 0.0001) \mathrm{H}-(6.27 \pm 0.07) \quad \mathrm{r}^{2}=0.96
$$

where $\mathrm{H}$ is the altitude in $\mathrm{m}$.

[11] The vertical oxygen isotopic gradient is $-0.18 \%$ / $100 \mathrm{~m}$; this value is close to that estimated by Hauser et al. [1980] $(-0.20 \% / 100 \mathrm{~m})$ and that estimated by Favara et al. [1998] $(0.21 \%$ o/100 m) in different areas in Sicily. A vertical oxygen isotopic gradient value, close to that observed in Sicily, was also found using the data obtained from stations located in several sites in Europe $(-0.21 \%$ o/100 m) [Poage and Chamberlain, 2001]. This suggests that it is not strongly dependent on local features. $\delta \mathrm{D}$ is also well related to altitude (Figure $4 b$ ) in accordance with the equation:

$$
\delta \mathrm{D} / \%=-(0.0085 \pm 0.0009) \mathrm{H}-(37.68 \pm 0.50) \quad \mathrm{r}^{2}=0.90
$$

from which a vertical hydrogen isotope gradient of $-0.85 \% / 100 \mathrm{~m}$ can be deduced.

[12] By plotting $d$ versus altitude (Figure 5), a good correlation was found. As shown in Figure 5 the correlation between $d$ and altitude is given by the equation:

$$
d / \%=(0.0061 \pm 0.0007) \mathrm{H}+(12.5 \pm 0.3) \quad \mathrm{r}^{2}=0.90
$$

Nevertheless we can distinguish three different groups: the six samples collected at an altitude of $<100 \mathrm{~m}$ a.s.l., fall in group A; they are located at random in a small range of $d$. The three samples with $400 \mathrm{~m}<$ altitude $<700 \mathrm{~m}$ a.s.l., fall in group B; they hardly ever show any $d$ variation. The two samples collected at an altitude $\approx 1,000 \mathrm{~m}$ a.s.1., fall in group $C$; they are located in the main reliefs of the studied area: M. Sparagio and M. Inici. These samples are characterized by comparatively very high values of $d$. As regards the samples belonging to group $\mathrm{C}$ we must take into account the contribution of the local orographic clouds. In fact, wherever a layer of air is subjected to an upward motion as a result of topographically induced wave motions and is sufficiently moist, a cloud will form [Houze, 1993]. Even in flows over small hills, orographic clouds can enhance local precipitations. Under these conditions, there is insufficient time for precipitation to form solely within the cloud. However, if there are small droplets falling from higher-level clouds, they will grow rapidly as they pass through the saturated air within the orographic cloud, producing bigger drops at the ground (by coalescence). This process is known as the seeder-feeder mechanism [Klemp, 1992; Houze, 1993].

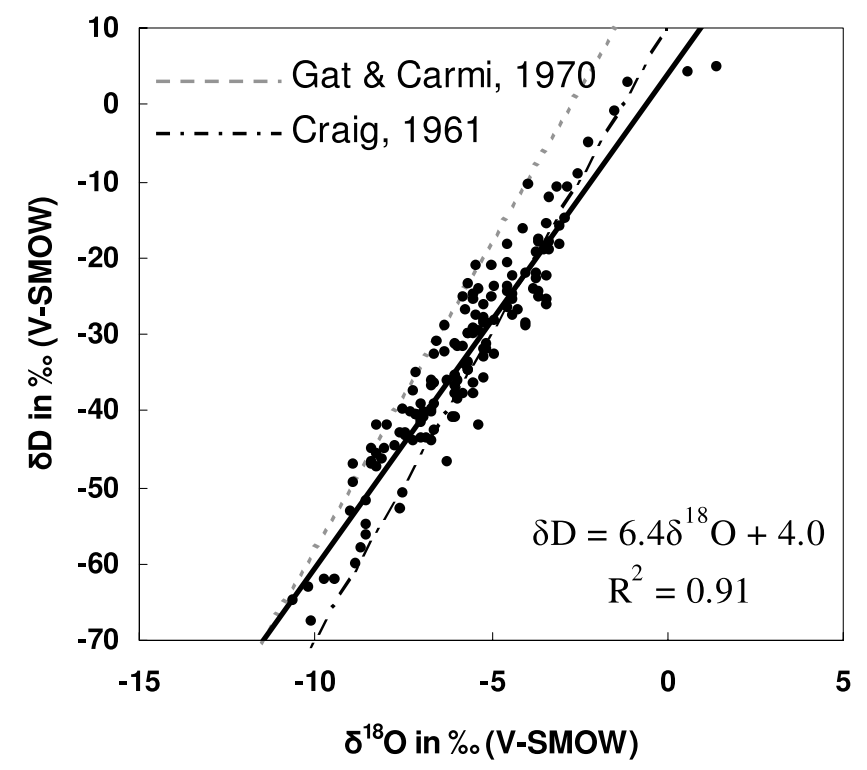

Figure 3. $\delta \mathrm{D} \%$ versus $\delta^{18} \mathrm{O} \%$ diagram. Monthly values of the period February 2002 to March 2003 are shown. 


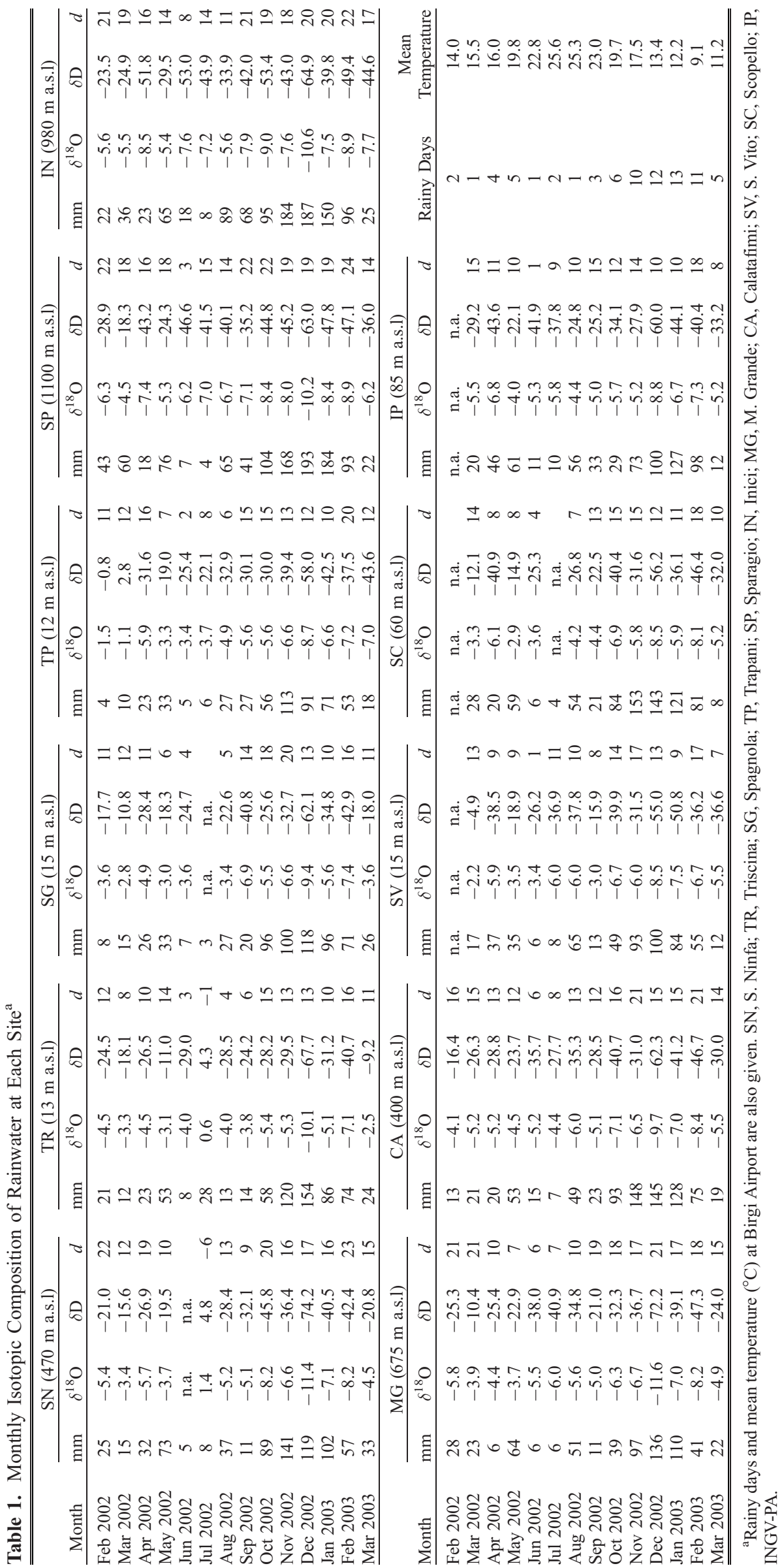


Table 2. Volume Weighted Average Annual Isotopic Composition and Computed d-Excess ${ }^{\mathrm{a}}$

\begin{tabular}{|c|c|c|c|c|c|c|c|}
\hline \multirow[b]{2}{*}{ Rain Gauge } & \multicolumn{5}{|c|}{ April 2002 to March 2003} & \multirow[b]{2}{*}{$\delta^{18} \mathrm{O}$} & \multirow[b]{2}{*}{ d-Excess } \\
\hline & Latitude & Longitude & Altitude, $\mathrm{m}$ asl & $\mathrm{mm}$ & $\delta \mathrm{D}$ & & \\
\hline S. Ninfa & $37^{\circ} 46^{\prime}$ & $12^{\circ} 53^{\prime}$ & 470 & 708 & -40.9 & -7.1 & 16.2 \\
\hline Triscina & $37^{\circ} 35^{\prime}$ & $12^{\circ} 48^{\prime}$ & 13 & 657 & -35.9 & -6.0 & 11.9 \\
\hline Spagnuola & $37^{\circ} 50^{\prime}$ & $12^{\circ} 28^{\prime}$ & 15 & 626 & -36.7 & -6.3 & 13.9 \\
\hline Trapani & $38^{\circ} 01^{\prime}$ & $12^{\circ} 32^{\prime}$ & 12 & 524 & -39.2 & -6.5 & 12.7 \\
\hline Sparagio & $38^{\circ} 03^{\prime}$ & $12^{\circ} 46^{\prime}$ & 1100 & 976 & -46.7 & -8.2 & 19.2 \\
\hline Inici & $38^{\circ} 00^{\prime}$ & $12^{\circ} 51^{\prime}$ & 980 & 1008 & -46.9 & -8.1 & 18.1 \\
\hline M. Grande & $37^{\circ} 53^{\prime}$ & $12^{\circ} 44^{\prime}$ & 675 & 590 & -43.2 & -7.4 & 15.9 \\
\hline Calatafimi & $37^{\circ} 52^{\prime}$ & $12^{\circ} 52^{\prime}$ & 400 & 775 & -40.9 & -7.1 & 16.1 \\
\hline San Vito & $38^{\circ} 10^{\prime}$ & $12^{\circ} 44^{\prime}$ & 15 & 555 & -40.0 & -6.5 & 12.3 \\
\hline Scopello & $38^{\circ} 02^{\prime}$ & $12^{\circ} 51^{\prime}$ & 60 & 752 & -37.7 & -6.3 & 12.5 \\
\hline Palermo & $38^{\circ} 09^{\prime}$ & $13^{\circ} 18^{\prime}$ & 85 & 657 & -38.7 & -6.3 & 11.7 \\
\hline
\end{tabular}

${ }^{\mathrm{a}}$ Coordinates of each site are also given.

[13] In the studied areas cap clouds can be seen all year round on the main reliefs, while several kinds of orographic clouds can be seen occasionally over inland areas.

[14] Because of the location of western Sicily's main reliefs, the main source of moisture is direct evaporation from the Mediterranean Sea. In fact, the poor vegetation coverage and the lack of significant evaporating water bodies in the inland area, have lead us to believe that recycled moisture is negligible with respect to maritime moisture. Orographic clouds form locally and we know that the Mediterranean Sea is a classic example of a reservoir producing water vapor characterized by high deuterium excess [Gat and Carmi, 1970; Gat et al., 2003]. Thus reasonably high values of $d$ should be found in orographic clouds. As far as the isotopic abundances are concerned, the process that enhances the size of the droplets may be approximately considered as being a mixing between two amounts of water having different isotopic compositions. In this hypothesis, if the relative fractions of seeder clouds and feeder clouds are known and the isotopic composition of the precipitation at the ground is given, the hypothetical deuterium excess of orographic clouds can be computed. A schematic illustration of the process is shown in Figure 6a in which the $d$ plotted values are of Scopello $(d=12.5$, $60 \mathrm{~m}$ a.s.l.) and M. Inici ( $d=18.1 ; 980 \mathrm{~m}$ a.s.l. $)$ sites. Since a very good correlation was found between the precipitation amounts of the two sites $\left(\mathrm{P}_{\text {Scopello }}=\mathrm{P}_{\text {M.Inici }} * 0.83, \mathrm{r}^{2}=0.95\right.$; where $\mathrm{P}$ is the amount of rain, Figure $6 \mathrm{~b}$ ), and as they are very close (horizontal distance $=6 \mathrm{Km}$, Figure 6c), we assume that the contribution of the higher clouds (generally with base altitude $>1,000 \mathrm{~m}$ a.s.l.) is the same for the two sites. We therefore estimated the orographic fraction of the precipitation to be about $17 \%$ of the total collected rain. Using these values an approximate mean value of $d$ close to 45 was computed for orographic clouds.

[15] This value is higher than that found by Gat et al. [2003] (ranging between 9.2 and 34.5\%o) for Mediterranean vapor, so that the origin of air masses cannot be considered the only factor producing deuterium enrichment. Moreover, rain samples showing deuterium excess values up to $40 \%$ have been found at Cheju Island (Korea) [Lee et al., 1999]. On this island the formation of cap clouds is a frequent process and for this reason it has been chosen for the ACEASIA aerosol-cloud interaction experiment [Bower et al., 2001].
[16] We cannot model the mean isotopic composition of the precipitation by analyzing only the monthly data because they strongly reflect seasonal variations. Furthermore the monthly samples often represent mixing between several rain events having different origins. Nevertheless, twice the monthly isotopic composition of the precipitation was in good agreement with the processes previously described. In fact, samples taken in February 2002 and
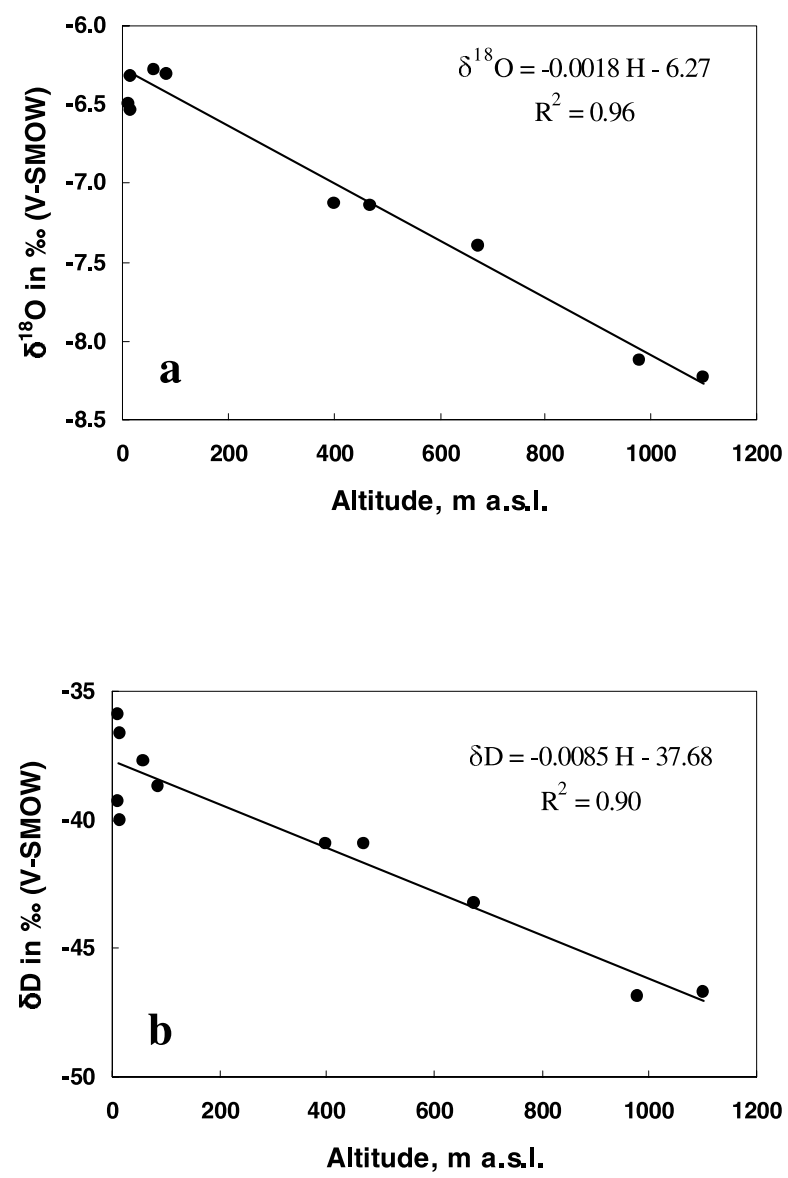

Figure 4. (a) Weighted $\delta^{18} \mathrm{O} \%$ values versus altitude (February 2002 to March 2003). (b) Weighted $\delta \mathrm{D} \%$ values versus altitude (February 2002 to March 2003). 


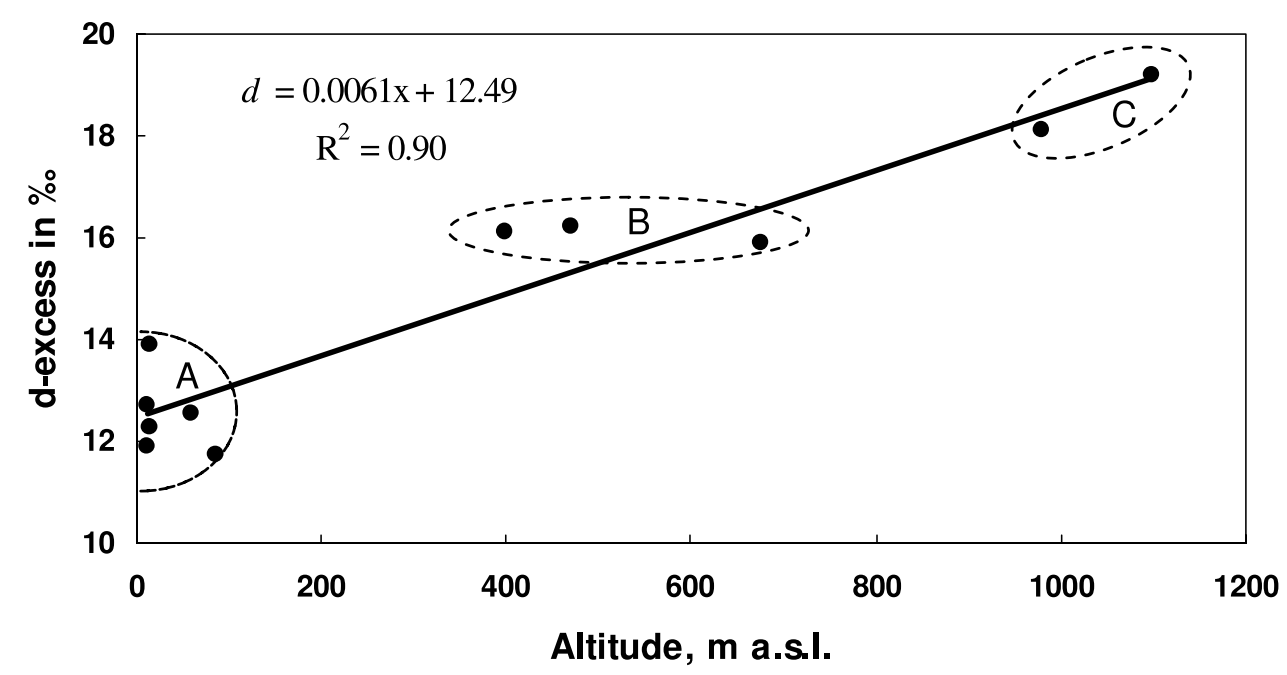

Figure 5. Weighted $d \%$ values versus altitude (February 2002 to March 2003).

January 2003 from the rain gauges situated along the coast, fit well with the Global Meteoric Water Line (GMWL) described first by Craig [1961], while the other samples show higher values of $d$ (Figure 7).

[17] In January 2003 group A samples fitted very well with GMWL $\left(\mathrm{R}^{2}=0.99\right)$; group B samples had intermediate $d$ values while group $\mathrm{C}$ samples had $d$ values about 10 units $\%$ higher than those of group A. If the different $d$ values were due to evaporation of rain during the fall, the group A samples should have been evaporated and, as a consequence, should have been enriched. Moreover, evaporated rain samples usually lie along low-slope lines [Yurtsever and Gat, 1981]. Since in this case these requirements were not verified, we assume that significant evaporation of rain during the fall did not occur. In addition, according to Stewart [1975], drops evaporating in atmospheres at intermediate and high relative humidity gradually attain equilibrium with the atmospheric vapor. Since relative humidity of the atmosphere column below 1,200 m a.s.l. is usually higher than $70 \%$ (Figure 7), evaporation, and consequently kinetic fractionation, is believed unlikely. Even though the isotopic effects, due to evaporation of rain, are believed negligible; further studies could supply additional tools to quantitatively estimate such effects.

[18] Storms generating precipitations in January 2003 came from the Atlantic Ocean (Figure 8). This particular case of samples fitting the GMWL suggests that general circulation processes and local fractionation phenomena didn't change the isotopic composition of the water vapor that generated precipitations.

\section{Local Meteoric Water Line}

[19] Having described the processes governing the isotopic composition of precipitations, we will now define the equation describing the Local Meteoric Water Line (LMWL):

$$
\delta \mathrm{D}=(4.70 \pm 0.32) \delta^{18} \mathrm{O}-(8.2 \pm 2.2) \quad \mathrm{r}^{2}=0.96
$$

The slope of the LMWL (Figure 9) is lower than that of the GMWL and of that defined in the same area by Favara et al. [1998]. As a result of the low value of the slope, the intercept is a negative number. Since stations at an altitude higher than $400 \mathrm{~m}$ a.s.l. are affected by local orographic clouds we also defined the LMWL* using data taken only from the coastline stations (Figure 9).

[20] The LMWL* equation is therefore:

$$
\delta \mathrm{D}=(7.00 \pm 1.84) \delta^{18} \mathrm{O}+(6.2 \pm 11.6) \quad \mathrm{r}^{2}=0.78
$$

The LMWL* may be considered representative of mesoscale processes. That's to say that coastline sites are not influenced by local features. High values of $d$ in sites situated at elevations higher than $400 \mathrm{~m}$ a.sl. (i.e., groups B and C), produce a "lever effect" that rotates the LMWL around the area of dots, which refer to the coastline sites (group A), that acts as a fulcrum (Figure 9).

[21] Most of the local groundwater [Liotta, 2004] fell within the GMWL and the MMWL (Mediterranean Meteoric Water Line) [Gat and Carmi, 1970]. However, they fell above the LMWL (Figure 10), which suggests that the groundwater is generally characterized by higher deuterium excess. The explanation of this comes from the spatial distribution of the rain. As well known, mountains represent the main recharge area of aquifers; the largest amount of precipitation in the area under study can be found at M. Sparagio and M. Inici, where high values of $d$ have been measured. This leads to high values of $d$ in the groundwater.

\section{What Can Enhance Deuterium Excess of Orographic Cloud Droplets?}

[22] Condensation processes have not been isotopically studied enough, whereas evaporation processes have been modeled by several authors [Craig and Gordon, 1965; Merlivat, 1970; Stewart, 1975; Merlivat, 1978; Cappa et al., 2003]. Diffusive transport leads to greater fractionation of the light isotopomers during nonequilibrium processes when molecular diffusion is important [Cappa et al., 2003]. As a result of the different diffusion rates of molecules ${ }^{1} \mathrm{H}_{2}^{16} \mathrm{O}{ }^{1} \mathrm{H}^{2} \mathrm{H}^{16} \mathrm{O}{ }^{1} \mathrm{H}_{2}^{18} \mathrm{O}$, kinetic fractionation processes could produce an excess of deuterium in the forming phase, 

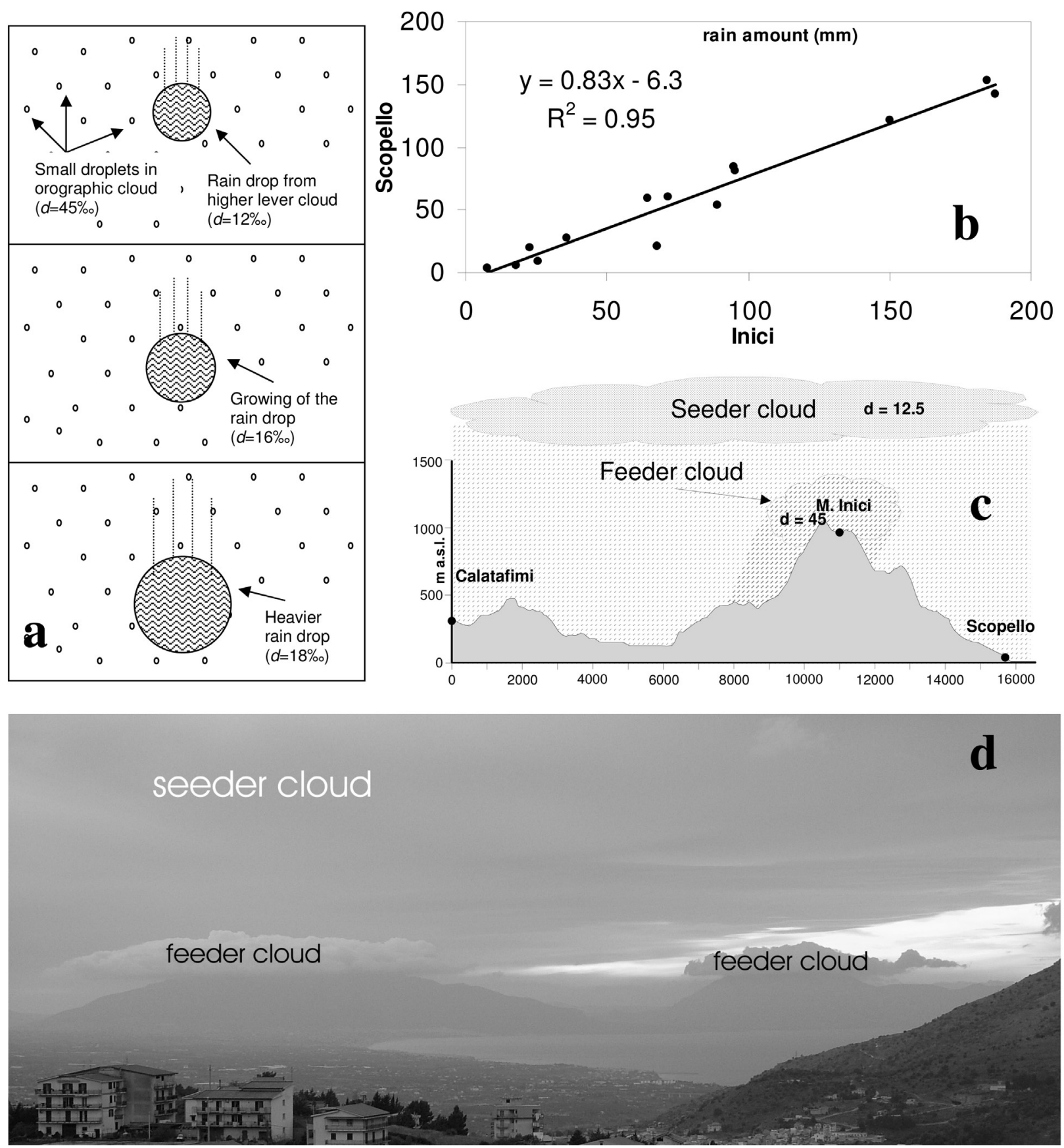

Figure 6. Isotopic effect of the seeder feeder mechanism: (a) growth of the drops coming from seeder clouds during their fall through orographic clouds (not in scale), (b) scattering diagram of monthly rain amounts collected at the Inici and Scopello sites, (c) schematic illustration of the seeder-feeder mechanism at Mount Inici, and (d) picture of Mount Inici (on the left) and Mount Sparagio (on the right) taken during a rainy day.

with respect to the content coming from equilibrium processes.

[23] The d-excess parameter is thought to be the most useful stable-isotope property for the characterization of vapor origin; it is essentially fixed at the site of sea-air interactions by the nonequilibrium transport processes involved [Craig and Gordon, 1965]. However, if local kinetic condensation processes do occur, the d-excess parameter may change. In fact solid precipitations often show higher d-values due to nonequilibrium rapid condensation during the growth of ice particles [Jouzel and Merlivat, 1984].

[24] The existence of an isotopic kinetic effect at vapor condensation was theoretically predicted by Stewart [1975]. According to Stewart [1975], condensation of drops in supersaturated atmospheres is the identically opposite process to drop evaporation in undersaturated atmospheres; so 

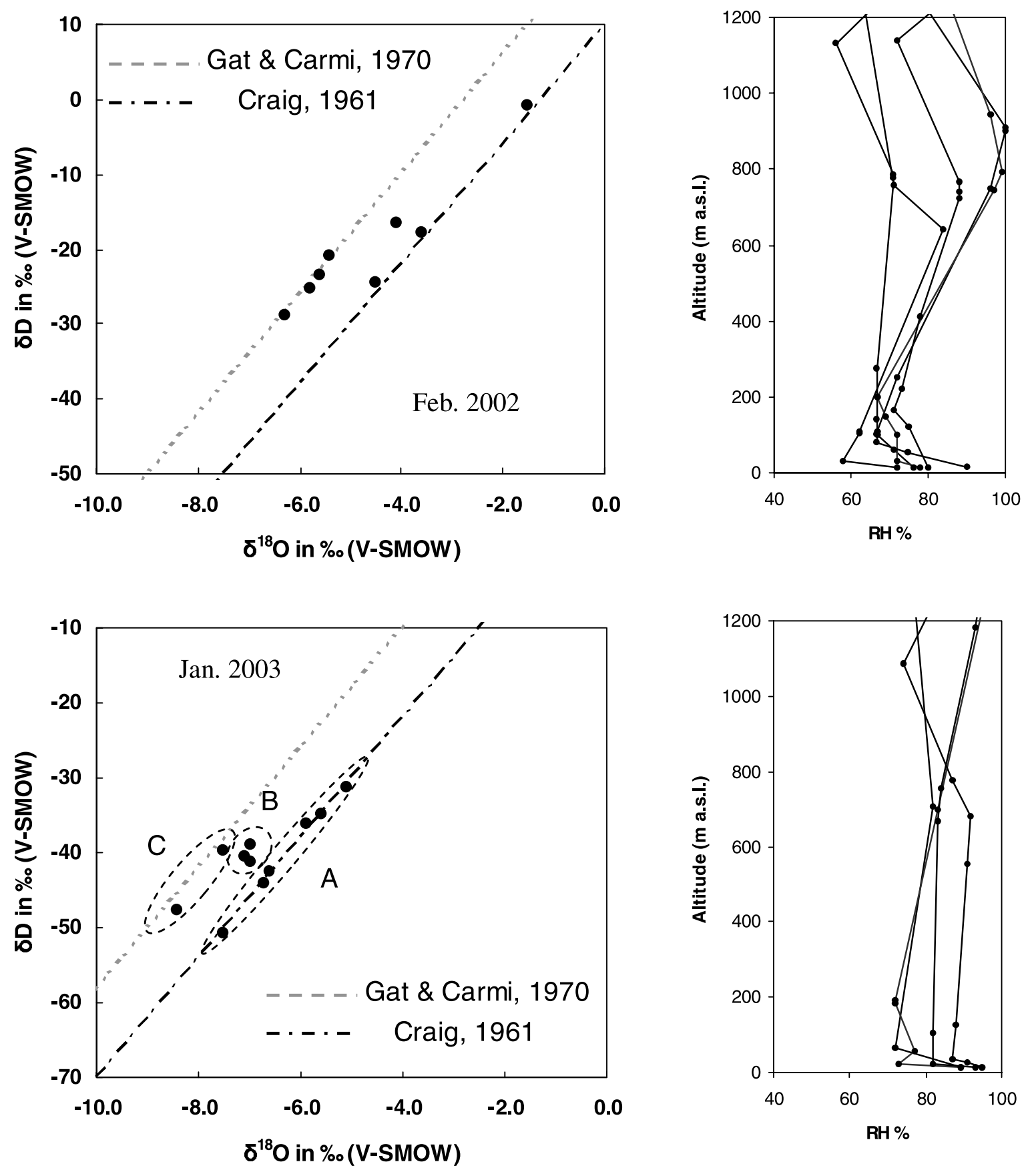

Figure 7. (top left) $\delta \mathrm{D} \%$ versus $\delta^{18} \mathrm{O} \%$ o diagram for monthly isotopic composition referred to February 2002. A few rainy days were registered in February 2002 and, on the basis of EUMETSAT images, air masses coming from the Atlantic Ocean probably generated orographic clouds also in M. Grande and S. Ninfa that showed values close to that of M. Inici and M. Sparagio. (top right) Vertical profiles of relative humidity (16429 LICT Trapani observations at 00Z 07, 06Z 07, 12Z 07, $18 \mathrm{Z} 07$ and 00Z 08). (bottom left) $\delta \mathrm{D} \%$ versus $\delta^{18} \mathrm{O} \%$ diagram for monthly isotopic composition referred to January 2003. (bottom right) Vertical profiles of relative humidity (16429 LICT Trapani observations at 06Z 24, $12 Z$ 24, $18 \mathrm{Z} 24$ and $00 \mathrm{Z} 25$ ).

equations for isotopic fractionation during evaporation of falling drops apply equally well to fractionation during condensation because the rate-limiting step in both processes is the diffusion of the vapor in the atmosphere. Although condensation of droplets is a nonequilibrium process, it usually seems to occur in isotopic equilibrium between cloud droplets and atmospheric vapor because super saturation in clouds is normally modest [Stewart, 1975]. Nevertheless, the 


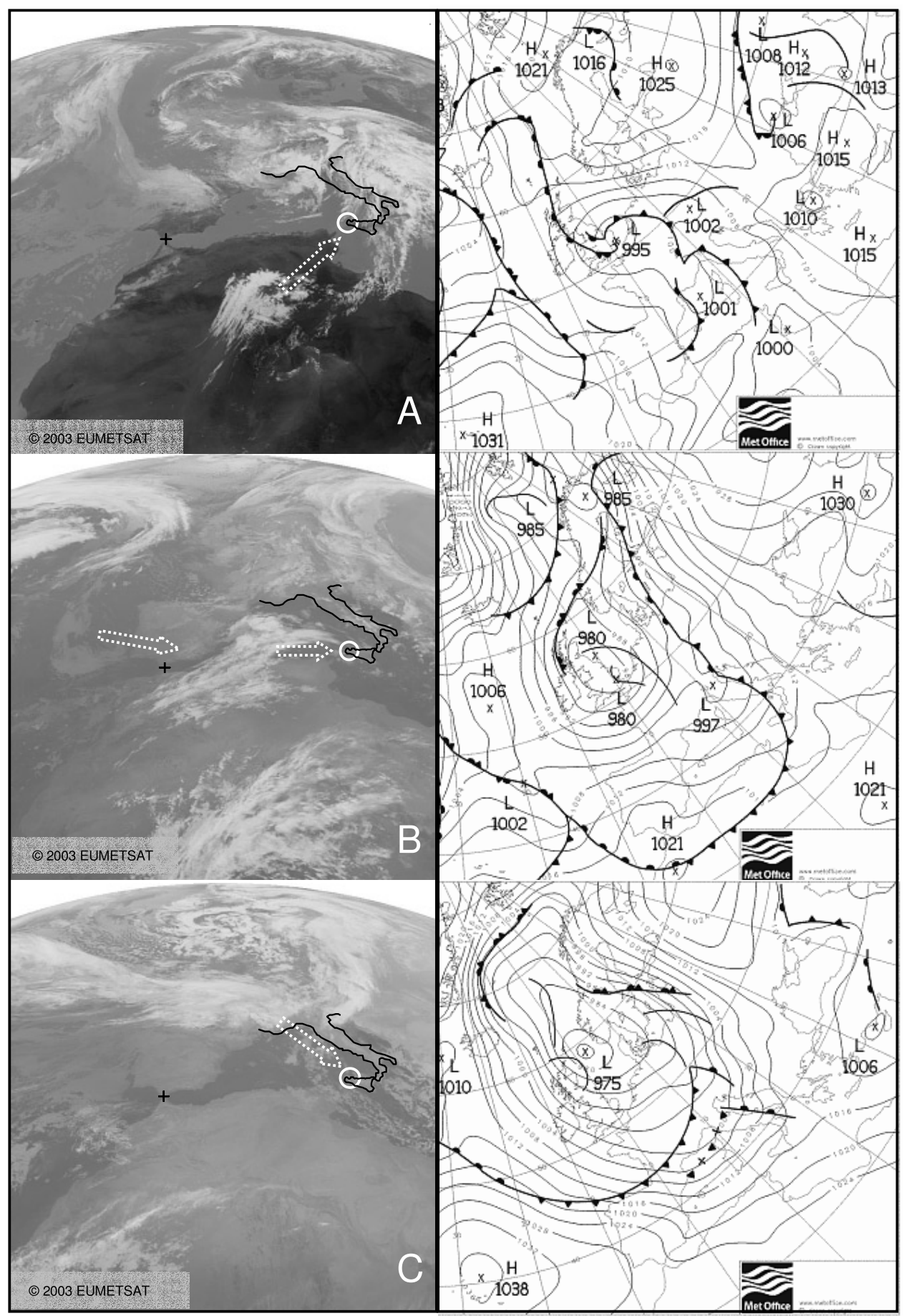

Figure 8. Selected infrared images and synoptic charts of Europe. (a) In June 2002 it rained mainly on the 6 and 7 June. The air masses came from the southwest. (b) In January 2003 it rained mainly on the 24 January. The air masses came from the Atlantic Ocean. (c) In February 2003 it rained mainly on the 4 February. The air masses came from the north (see text for details). Images on the left were provided by EUMETSAT dissemination service, and images on the right are (C) British Crown copyright 2006, published by the Met Office UK.

first step in droplet formation implies the diffusion of water molecules around the condensation nuclei; therefore kinetic effects should be expected to occur. When clouds form, it takes a long time before rain starts to fall, therefore the droplets have enough time to reach isotopic equilibrium with the surrounding vapor. In orographic clouds the life time of droplets is always very short since they form where a lifting is induced by orography and dissolve quickly when surround- 


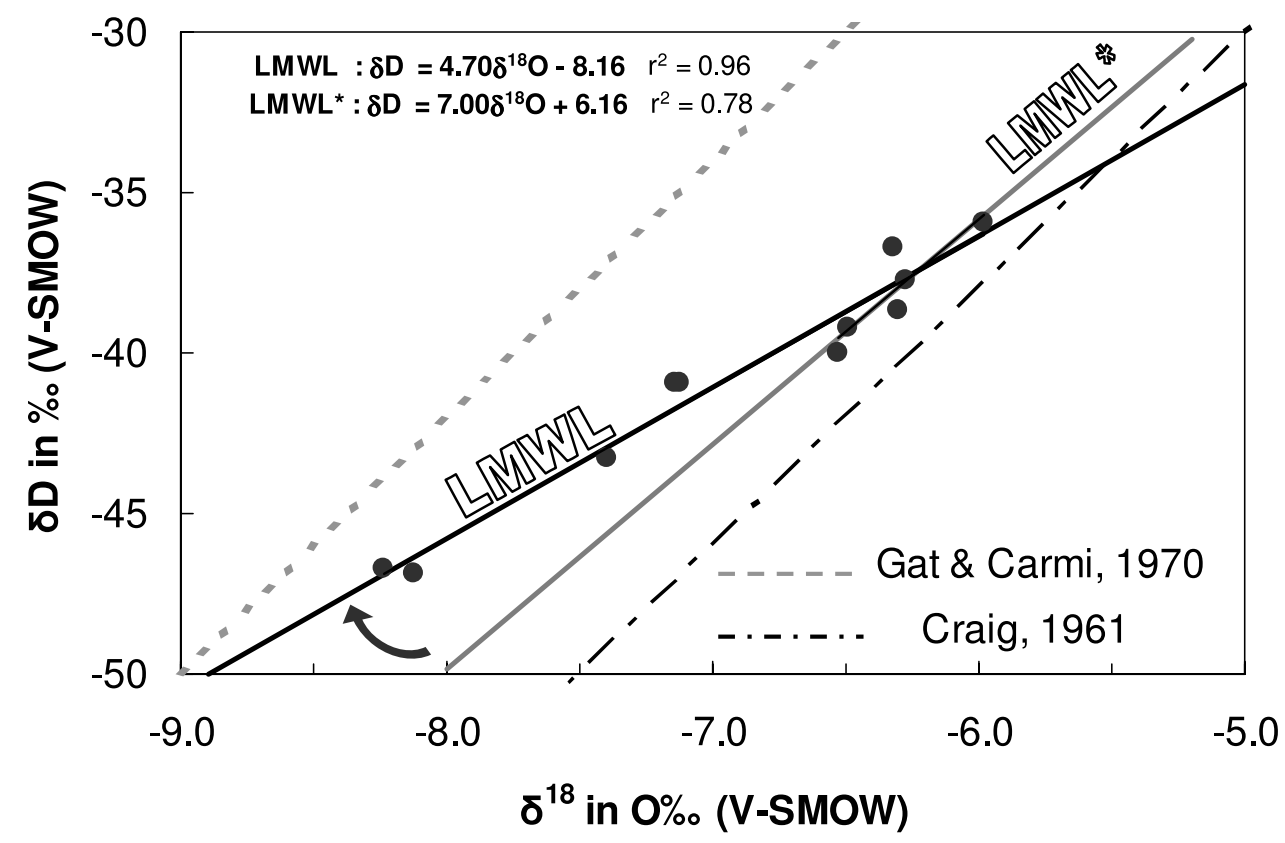

Figure 9. Local Meteoric Water Lines (LMWL and LMWL*) plotted and compared to the Global Meteoric Water Line (GMWL) defined by Craig [1961] and to the Mediterranean Meteoric Water Line (MMWL) defined by Gat and Carmi [1970]. Mean volume weighted values have been used (see text for details).

ing conditions are reestablished. Under these conditions in-cloud droplets cannot be in isotopic equilibrium with the surrounding vapor. Therefore the liquid phase may be at last enriched in deuterium.

\section{Hypothetical Isotopic Composition of Orographic Cloud Droplets}

[25] Orographic clouds can be considered as being a particular kind of fog, so that some information about their isotopic composition may by deduced from studies of that phenomena. However, we must take into account the fact that none of the fog collectors can avoid isotopic exchange and, hence, reequilibration between the liquid phase and vapor. Generally fog is isotopically enriched compared to local rain [Gonfiantini and Longinelli, 1962; Aravena et al., 1989; Ingraham and Matthews, 1995; Scholl et al., 2002]. A famous example of upslope fog that occurs during the formation of orographic clouds may be observed in Hawaii. Scholl et al. [2002] analyzed the isotopic composition of fog collected at East Maui; the collected samples showed an isotopic signature that was more enriched than that of the local rainfall. Harris et al. [1999] found high values of deuterium excess in the groundwater of Table Mountain (Cape Peninsula, South Africa). The area, characterized by a typically Mediterranean climate, is famous for the cap cloud that forms over the top of the mountain that enhances the amount of local precipitation. Springs on the slopes of Table Mountain show d values about 5\% higher than the groundwater collected a few kilometers to the south, in the Cape Flats Aquifer. The mechanism proposed in this paper would justify the observation of Harris et al. [1999].

[26] The isotopic composition of orographic cloud droplets is expected to be enriched both in ${ }^{18} \mathrm{O}$ and in $\mathrm{D}$, since it represents the first step in the condensation of marine vapor and it also is expected to have high values of deuterium excess as previously discussed. In Figure 11, the hypothetical isotopic composition of orographic cloud droplets is plotted. (see caption for detail).

\section{Temporal Variation of Deuterium Excess}

[27] If we analyze the temporal variation of $d$, some useful information on the mesoscale circulation paths can

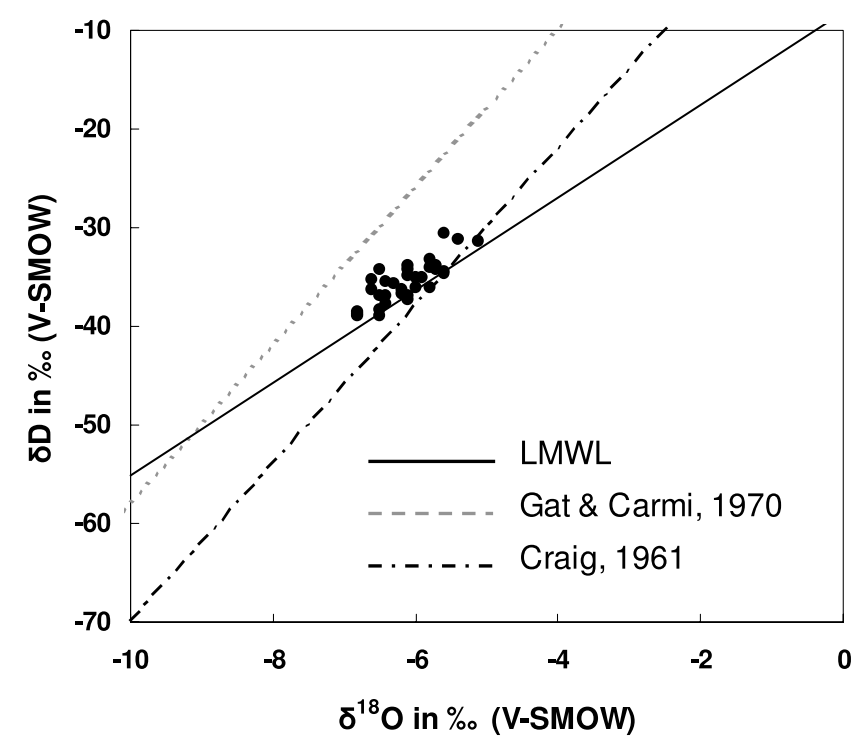

Figure 10. $\delta \mathrm{D} \%$ o versus $\delta^{18} \mathrm{O} \%$ diagram. Local groundwater samples are plotted. The LMWL, GMWL and MMWL are also drawn. 


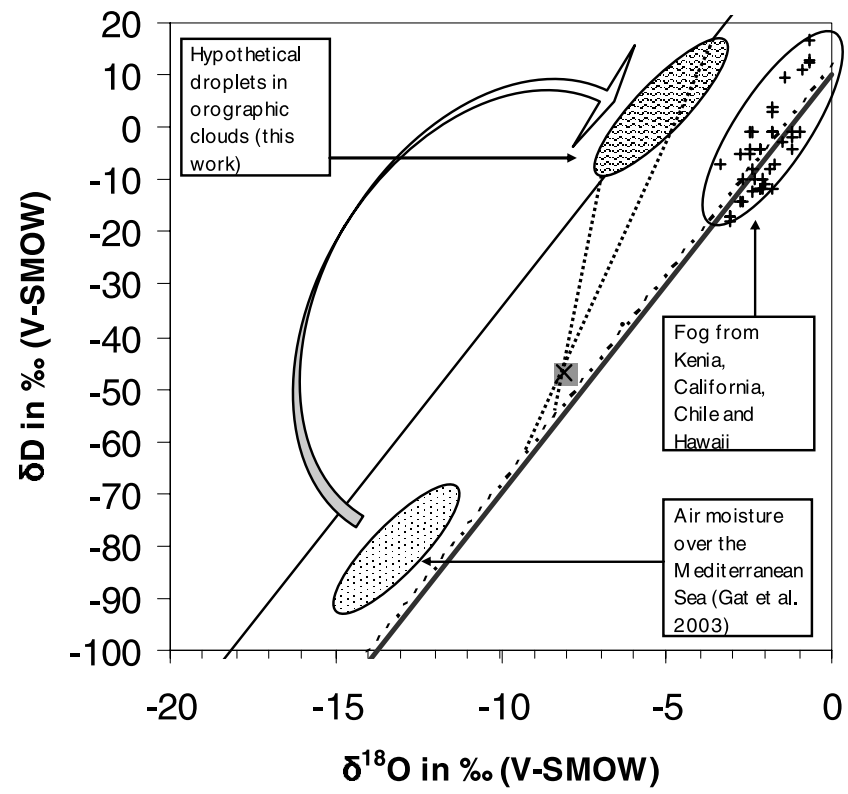

Figure 11. $\delta \mathrm{D} \%$ versus $\delta^{18} \mathrm{O} \%$ diagram. The solid bold line indicates the GMWL $(d=10)$. The dashed line has $d=12.5$ (i.e., the average mean weighted values of the coastal sites). The solid line has $d=45$ (i.e., the computed deuterium excess for orographic cloud droplets). The shaded dot indicates the mean weighted composition of the precipitation at Mount Inici. The dotted lines indicate the two possible mixing lines between orographic cloud water and higher-level cloud water. be deduced. In Figure 12 mean weighted values of $d$ have been compared with the mean values of Global Network for Isotopes in Precipitation (GNIP) database computed by Araguás-Araguás et al. [2000] for the Northern Hemisphere, and with the mean monthly temperatures of western Sicily. The high seasonal variation in d-excess between summer and winter reflects the climatic features and circulation patterns of the studied area. In fact, when cold air masses, characterized by low relative humidity, travel over seawater, kinetic fractionation produces high deuterium excess values in the vapor, whereas the movement of warm air masses, usually characterized by high relative humidity, leads to lower deuterium excess values. According to the above mentioned theoretical considerations., during June 2002 hot air masses came from Algeria (Figure 8a) and produced precipitations with a very low deuterium excess, whereas in February 2003 cold air masses coming from the North Sea produced precipitation with very high values of $d$ (Figure 8c).

\section{Conclusions and Implications}

[28] The mean isotopic composition of the precipitation in the studied area is similar along the coast line, whereas it changes slightly in inland areas and more significantly over hills. The local contribution of orographic clouds to the total amount of rainfall in the studied area has been taken into consideration. The local vapor forms mainly on the Mediterranean Sea, which is a classic example of reservoir producing water vapor characterized by high deuterium excess. However, the high values of $d$ found in the precip-

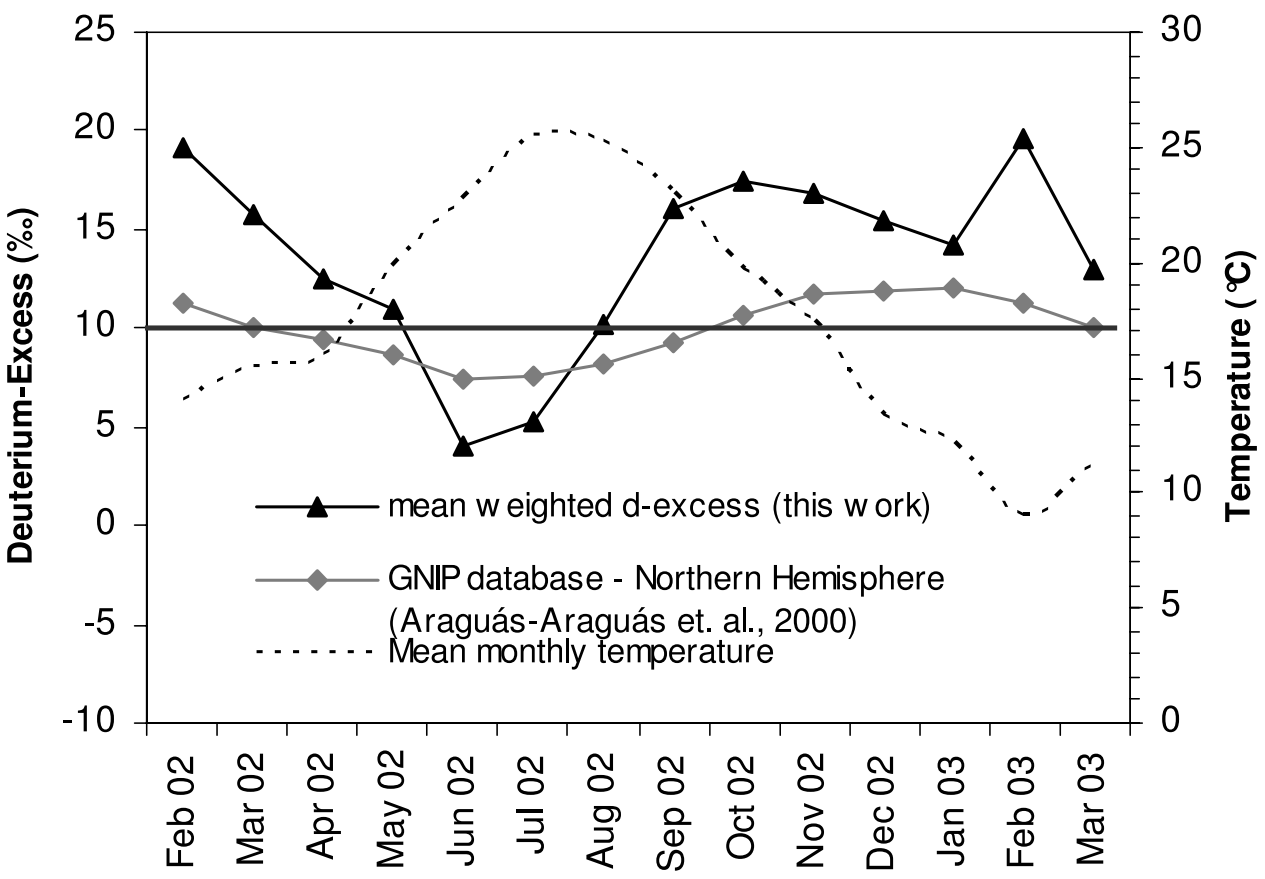

Figure 12. Deuterium-excess versus time. Mean weighted d-excess values of the period February 2002 to March 2003 are compared with the mean values of Global Network for Isotopes in Precipitation (GNIP) database computed by Araguás-Araguás et al. [2000] for the Northern Hemisphere and mean monthly temperature of western Sicily (Trapani Birgi Airport). The high shifts in d-excess between the summer and winter periods are due to the climatic features of the studied area. 
itation of the main reliefs can only be explained by invoking another factor able to enhance deuterium excess.

[29] Similarly to evaporation, when droplets of orographic clouds form, the higher diffusivity of ${ }^{1} \mathrm{H}^{2} \mathrm{H}^{16} \mathrm{O}$, with respect to ${ }^{1} \mathrm{H}_{2}^{18} \mathrm{O}$, produces an enrichment of deuterium in the liquid phase. Droplet formation may be considered a mainly diffusive process, so that a kinetic effect is expected, whereas after formation, isotopic exchange leads to isotopic equilibrium with the surrounding vapor.

[30] We have modeled the isotopic evolution of rain falling through orographic clouds (seeder-feeder mechanism) that partially contributes to the total amount of rainfall at the ground. On the basis of the relative contribution of seeder and feeder clouds, the mean hypothetical deuterium excess value of orographic clouds has been computed to be close to 45 . In addition, the droplets of the orographic clouds should be enriched as they represent the first condensate fraction of the surrounding marine vapor. The high values of deuterium excess computed for orographic cloud droplets have been discussed taking into account the fact that kinetic fractionation during condensation can also occur.

[31] The results obtained also imply that where orographic precipitations occur, the local isotopic composition could shift significantly with respect to the surrounding areas.

[32] Even though the process has been described in the central Mediterranean area, which is characterized by peculiar features, the orographic d-excess contribution could well change the isotopic composition of precipitation significantly wherever orographic clouds form.

[33] Acknowledgments. This paper, part of the Ph.D. thesis by M.L., was supported by the European Social Fund and by the Istituto Nazionale di Geofisica e Vulcanologia. The work reported in this paper was in part presented at the International Workshop on the Application of Isotope Techniques in Hydrological and Environmental Studies (UNESCO, Paris, 6-8 September 2004), held to honor the memory of Jean-Charles Fontes, ten years after his death. Thanks to Met Office UK (C) British Crown copyright 2006) and EUMETSAT dissemination service that provided synoptic charts and satellite images, respectively.

\section{References}

Araguás-Araguás, L., K. Froehlich, and K. Rozanski (2000), Deuterium and oxygen-18 isotope composition of precipitation and atmospheric moisture, Hydrol. Processes, 14, 1341-1355.

Aravena, R., O. Suzuki, and A. Pollastri (1989), Coastal fog and its relation to the groundwater in the IV region of northern Chile, Chem. Geol., 79, $83-91$.

Bolle, H.-J. (2003), Mediterranean Climate: Variability and Trends, Springer, New York.

Bower, K. N., et al. (2001), The ACE-Asia aerosol-cloud interaction experiment, Abstracts of the European Aerosol Conference, Leipzig, Germany, September 3rd-11th 2001, J. Aerosol Sci., 32, suppl. 1, S971- 972 .

Cappa, C. D., M. B. Hendricks, D. J. DePaolo, and R. C. Cohen (2003), Isotopic fractionation of water during evaporation, J. Geophys. Res., 108(D16), 4525, doi:10.1029/2003JD003597.

Celle-Jeanton, H., Y. Travi, and B. Blavoux (2001), Isotopic typology of the precipitation in the western Mediterranean region at three different time scales, Geophys. Res. Lett., 28(7), 1215-1218.

Craig, H. (1961), Isotopic variations in meteoric waters, Science, 133, $1702-1708$.

Craig, H., and L. I. Gordon (1965), Deuterium and oxygen-18 variations in the ocean and the marine atmosphere, in Proceedings of a Conference on Stable Isotopes in Oceanographic Studies and Paleotemperatures, Spoleto, July 26-27, edited by E. Tongiorgi, pp. 9-130, Lab. of Geol. and Nucl. Sci., Pisa, Italy.

Cruz-San Julián, J., et al. (1992), Sources of precipitation over south-eastern Spain and groundwater recharge, An isotopic study, Tellus, Ser. B, 44, $226-236$.
Dansgaard, W. (1964), Stable isotopes in precipitation, Tellus, 16, 436468.

Epstein, S., and T. K. Mayeda (1953), Variations of the O-18 content of waters from natural sources, Geochim. Cosmochim. Acta, 4, 213-224.

Favara, R., F. Grassa, S. Ingaggiato, and F. D’Amore (1998), Geochemical and hydrogeological characterization of thermal springs in western Sicily, Italy, J. Volcanol. Geotherm. Res., 84, 125-141.

Gat, J. R., and I. Carmi (1970), Evolution of the isotopic composition of atmospheric waters in the Mediterranean Sea area, J. Geophys. Res., 75, 3039-3048.

Gat, J. R., B. Klein, Y. Kushnir, W. Roether, H. Wernli, R. Yam, and A. Shemesh (2003), Isotope composition of air moisture over the Mediterranean Sea: An index of the air-sea interaction pattern, Tellus, Ser. B, 55, $953-965$

Gonfiantini, R., and A. Longinelli (1962), Oxygen isotopic compositions of fog and rains from the North Atlantic, Experientia, 18, 222-223.

Harris, C., B. M. Oom, and R. E. Diamond (1999), A preliminary investigation of the oxygen and hydrogen isotope hydrology of the greater Cape Town area and an assessment of the potential for using stable isotopes as tracers, Water $S A, 25,15-24$.

Hauser, S., G. Dongarra, R. Favara, and A. Longinelli (1980), Composizione isotopica delle pioggie in Sicilia. Riferimenti di base per studi idrogeologici e relazione con altre aree mediterranee, Rend. Soc. Ital. Mineral. Petrol., 36, 671-680.

Houze, R. A., Jr. (1993), Cloud Dynamics, Int. Geophys. Ser., vol. 53, pp. 502-538, Elsevier, New York.

Ingraham, N. L., and R. A. Matthews (1995), The importance of fog drip water to vegetation: Point Reyes Peninsula, California, J. Hydrol., 164, $269-285$.

International Atomic Energy Agency (2005), Isotopic composition of precipitation in the Mediterranean Basin in relation to air circulation patterns and climate, IAEA TECDOC Ser. 1453, Vienna, Austria.

Jouzel, J., and L. Merlivat (1984), Deuterium and oxygen-18 in precipitation: Modelling of the isotopic effects during snow formation, J. Geophys. Res., 89, 11,749-11,757.

Kendall, C., and T. B. Coplen (1985), Multisample conversion of water to hydrogen by zinc for stable isotope determination, Anal. Chem., 57, $1437-1440$

Klemp, J. B. (1992), Mountains, effect on airflow and precipitation, in Encyclopedia of Earth System Science, vol. 3, pp. 251-262, Elsevier, New York.

Lee, K. S., D. B. Wenner, and I. S. Lee (1999), Using H- and O-isotopic data for estimating the relative contributions of rainy and dry season precipitation to groundwater: Example from Cheju Island, Korea, J. Hydrol., 222, 65-74.

Liotta, M. (2004), Geochemical processes governing groundwater composition in north-western Sicily: Isotopic model and water rock interaction, Ph.D. thesis, Univ. Palermo, Palermo, Italy.

Merlivat, L. (1970), Quantitative aspects of the study of water balance in lakes using the deuterium and oxygen-18 concentration in the water, in Isotope Hydrology, pp. 89-107, Int. At. Energy Agency, Vienna.

Merlivat, L. (1978), Molecular diffusivities of $\mathrm{H}_{2}^{16} \mathrm{O}, \mathrm{HD}^{16} \mathrm{O}$, and $\mathrm{H}_{2}^{18} \mathrm{O}$ in gases, J. Chem. Phys., 69, 2864-2871.

Poage, M. A., and C. P. Chamberlain (2001), Empirical relationships between elevation and the stable isotope composition of precipitation and surface waters: Considerations for studies of paleoelevation change, Am. J. Sci., 301, 1-15.

Rindsberger, M., M. Magaritz, I. Carmi, and D. Gilad (1983), The relation between air mass trajectories and the water isotope composition of rain in the Mediterranean Sea area, Geophys. Res. Lett., 10, 43-46.

Rozanski, K., L. Araguas-Araguas, and R. Gonfiantini (1992), Relation between long-term trends of oxygen-18 isotope composition of precipitation and climate, Science, 258, 981-985.

Scholl, M. A., S. B. Gingerich, and G. W. Tribble (2002), The influence of microclimates and fog on stable isotope signatures used in interpretation of regional hydrology: East Maui, Hawaii, J. Hydrol., 264, 170-184.

Stewart, M. K. (1975), Stable isotope fractionation due to evaporation and isotopic exchange of falling waterdrops: Application to atmospheric processes and evaporation of lakes, J. Geophys. Res., 80, 1133-1146.

Yurtsever, Y., and J. R. Gat (1981), Atmospheric waters, in Stable Isotope Hydrology, edited by J. R. Gat, and R. Gonfiantini, pp. 103-142, Int. At. Energy Agency, Vienna.

R. Favara and M. Liotta, Istituto Nazionale di Geofisica e VulcanologiaSezione di Palermo, Via U. La Malfa 153, I-90146 Palermo, Italy. (favara@pa.ingv.it; mliotta@pa.ingv.it)

M. Valenza, Dipartimento di Chimica e Fisica della Terra, Università degli Studi di Palermo, Via Archirafi 36, I-90123 Palermo, Italy. (mvale@ unipa.it) 